\title{
Smart Café Cities: Testing Human Capital Externalities in the Boston Metropolitan Area
}

\author{
Shihe Fu \\ Department of Economics \\ Boston College
}

January 6, 2005

\begin{abstract}
Existing studies have explored either only one or two of the mechanisms that human capital externalities percolate at only macrogeographic levels. This paper, by using the 1990 Massachusetts census data, tests four mechanisms at the microgeographic levels in the Boston metropolitan area labor market. We propose that individual workers can learn from their occupational and industrial peers in the same local labor market through four channels: depth of human capital stock, Marshallian labor market externalities, Jacobs labor market externalities, and thickness of the local labor market. We find that all types of human capital externalities are significant across census tracts and blocks. Marshallian labor market externalities and the effect of labor market thickness in terms of industry employment density are significant at the block level. The mechanisms of knowledge spillovers vary across industries and occupations. Different types of externalities attenuate at different speeds over geographic distances. The effect of labor market thickness - in terms of industry employment density - decays rapidly beyond 1.5 miles away from block centroid; the effect of human capital depth decays rapidly beyond three miles; while Jacobs externalities decay very slowly, indicating a certain degree of urbanization economies. We conclude that knowledge spillovers are very localized within microgeographic scope in cities that we call, "Smart Café Cities."

JEL Code: C21, R23, J24

\footnotetext{
${ }^{0}$ I am very grateful to Professors Richard Arnott, Stephen Ross, Marvin Kraus,

Email: fush@bc.edu. Website: www2.bc.edu/ fush.
} and participants of the AREUEA 18th Annual Doctoral Session for their very helpful comments. I also thank Jim Davis for all his help while I was working at the Boston Census Research Data Center. Financial support from the Lincoln Institute of Land Policy Dissertation Fellowship and Boston College Summer M. Michael Mann Fellowship are gratefully acknowledged. This paper has been screened to insure that no confidential data are revealed.
\end{abstract}


Even walking with any two other people, I will always find a teacher among them.

Confucius, Analects, Book 7, 21

Most of what we know we learn from other people. We pay tuition to a few of these teachers ... but most of it we get for free, and often in ways that are mutual - without a distinction between student and teacher ... What can people be paying Manhattan or downtown Chicago rents for, if not for being near other people?

-Robert E. Lucas, Jr., 1988, p.38-39

Existing studies have explored either only one or two of the mechanisms that human capital externalities percolate at only macrogeographic levels. The contribution of this paper, by using the 1990 Massachusetts census data, is to provide empirical evidence for four mechanisms at microgeographic levels. We test four channels through which individual workers can learn from their occupational and industrial peers in the same local labor market: depth of human capital stock, Marshallian labor market externalities, Jacobs labor market externalities, and thickness of the local labor market. We find that all these channels are strong and significant - but at different geographic scales - and they attenuate spatially at different speeds. We conclude that knowledge spillovers are very localized within microgeographic scope in cities that we call, "Smart Café Cities."

This paper is organized as follows: section 1 is the introduction, section 2 proposes four percolation channels of human capital externalities, and section 3 discusses the geographic scope of human capital externalities. Section 4 specifies the econometric models and discusses the identification strategies, section 5 introduces the dataset, section 6 presents the estimate results, and section 7 concludes.

\section{Introduction}

A high concentration of skilled workers can promote the creation, diffusion, acquisition, and accumulation of knowledge across individual workers, geographic 
space, and time. Workers benefit from being close to a dense skilled labor market where, through different channels, they can learn from others without compensation. For example, "if one man starts a new idea, it is taken up by others and combined with suggestions of their own; and thus it becomes the source of new ideas" (Marshall, 1920, p.271). Such productivity-enhancing external benefits of labor markets are called human capital externalities, knowledge spillover effects, learning externalities, or labor market local agglomeration economies, whichever you choose. Uncompensated externalities from aggregate human capital stock have long been considered one of the important forces of economic growth (Romer, 1986; Lucas, 1988). Further, local human capital externalities are considered to be one of the predominant reasons for the existence of cities (Henderson, 1974; Fujita and Ogawa, 1982; Lucas, 2001) and urban endogenous growth (Palivos and Wang,1996; Eaton and Eckstein 1997; Black and Henderson, 1999).

If workers can learn from others nearby, their productivity will increase. Therefore, firms would be willing to pay higher wages (assuming workers are paid by their marginal value of product). In order to prevent all workers from concentrating in a particular area, housing and land rents must increase to achieve spatial equilibrium. Therefore, firm data, wage data, and housing or land price data can be used to test human capital externalities. The disadvantage of using firm data is that it requires a broad set of control variables to separate other sources of benefit firms obtain from being close to each other, such as natural advantage, input sharing, and forward or backward linkages. Land prices usually are not directly observable. Estimating hedonic housing models to infer human capital externalities is reasonable, but omits information of individual workers. Other indirect methods may be possible; for example, Jaffe et al. (1993) used patent citation data to study the geographical localization of patent citations. The ideal direct way to identify human capital externalities is to employ wage data. A good example is the paper by Wheaton and Lewis (2002) that used wage data to test labor market agglomeration across Metropolitan Statistical Areas (MSAs). 
Two important questions have not yet been answered in the literature. The first question is what are the microfoundations of knowledge spillovers? Or, put another way, how do human capital externalities percolate? Though people do exchange information and ideas and learn from each other by socializing in downtown cafés, unfortunately, we can not directly observe how knowledge spills out among buildings and across streets. We hypothesize, by distilling the existing literature, that there exist the similar mechanisms of agglomeration economies in a dense labor market as those of firms' concentration, ${ }^{1}$ and interpret the positive effects of local labor market agglomeration on individual earnings as the evidence of human capital externalities. We propose that workers can learn from their occupational and industrial peers who are in the same local labor market through four channels:

(1) the depth (quality) of human capital stock in the local labor market;

(2) Marshallian labor market externalities, or the specialization and peer competition effects;

(3) Jacobs labor market externalities, or the diversity of the local labor market in terms of occupations and industries;

(4) the thickness (density) of local labor market or labor market pooling effects.

The second question is what is the geographic scope of human capital externalities? For example, at what geographic level are human capital externalities the strongest and most significant? How do knowledge spillovers attenuate spatially? Geographical proximity reduces communication costs and increases the frequency of social interactions. Intuitively, knowledge spillovers through social interactions are very localized. However, most empirical papers have used data only at metropolitan (Wheaton and Lewis, 2002), city or county (Timothy and Wheaton, 2001), or zip code level (Rosenthal and Strange, 2001).

The 1990 Massachusetts census data enable us to explore labor market agglomeration down to the census tract and block level. We estimate hedonic wage

\footnotetext{
${ }^{1}$ For a survey of literature on agglomeration economies from the concentration of firms or industries, see Rosenthal and Strange(2003b) and Duranton and Puga (2003).
} 
models with different location fixed effects and identify that almost all types of human capital externalities are significant across blocks as well as across tracts. Furthermore, Marshallian labor market externalities and the effect of labor market thickness in terms of industrial employment density are significant at the block level. We also estimate a spatial attenuation effects model, and find that different types of human capital externalities attenuate with distance at different speeds. For example, occupational Marshallian labor market externalities decay rapidly beyond 1.5 miles away from block centroid; the effect of human capital depth decays rapidly beyond three miles; while the effect of industry diversity decays slowly within nine miles. Since human capital externalities are very localized, we call dense urban areas "Smart Café Cities."2

\section{The Microfoundations of Human Capital Ex- ternalities}

Existing studies have explored either only one or two of the dimensions of knowledge spillover mechanisms. For example, Jovanovic and Rob (1989), Rauch(1993), Simon and Nardinelli (2002), and Shapiro (2003) studied only the depth of human capital. Wheaton and Lewis (2002) tested Marshallian labor market externalities and the thickness of a labor market. Ciccone and Hall (1996) studied only the density of economic activity. Jacobs labor market externalities have never been tested in literature. Charlot and Duranton (2003) identified that workplace communication externalities can explain only about one tenth of the effects of city size and average urban schooling on individual earnings, which hints that there must exist other channels of knowledge spillovers.

We propose that there are four types of percolation mechanisms of human capital externalities through local labor markets: depth (quality) of human capital stock, Marshallian labor market externalities, Jacobs labor market externalities, and thickness of labor markets. These four channels capture the four

\footnotetext{
${ }^{2}$ The term "Smart Cities" was proposed by Shapiro (2003). "Café Cities" was proposed by Professor Richard Arnott in his lectures on urban economics at Boston College.
} 
dimensions of knowledge: the vertical and horizontal difference, local specialization, and spatial density of knowledge. They can be considered as the local labor market attributes that promote human capital accumulation and enhance workers' productivity.

In the following subsections, we define the four types of human capital externalities in detail and design a set of variables to measure them. Our unique dataset enables us to test these four types of human capital externalities within one model specification.

\subsection{The Depth of Human Capital Stock}

We define the degree of advancement or sophistication of a certain type human capital as the depth or quality of human capital, which reflects the vertical difference of knowledge. Workers can learn more and faster from others who have better human capital in their fields than from those with lower human capital level. High-quality human capital can enhance the ability to absorb existing ideas and create new ones. Therefore, even though well-educated workers may learn less from less educated neighbors, they still learn much from the concentration of well-educated peers.

School education is the typical way to deepen human capital; therefore, the average level of education in a labor market is a good proxy for the depth of human capital stock. We use a simpler index: the share of workers with college degree, or higher, in a labor market, since an increase in the share of college graduates in a labor market implies an increase in the average level of education. ${ }^{3}$

A comprehensive literature survey on human capital externalities - in terms of the average level of education - was done by Moretti (2003). The first theoretical model incorporating human capital depth probably was constructed by Jovanovic and Rob (1989). Their model shows that knowledge spillovers depend on the vertical differences in what people know. Rauch (1993) provided probably

\footnotetext{
${ }^{3}$ Working experience is also a good measurement of human capital depth; but, Rauch (1993) found that the average level of education has a much greater external effect on wages than the average level of experience.
} 
the first empirical test of the effects of human capital depth on urban wages and land rents. He used the 1980 census data on individual workers in over 200 U.S. Standard Metropolitan Statistical Areas (SMSAs) and found that a metropolitan area with an average educational level one-year higher than another would have about a $3 \%$ productivity advantage. Simon and Nardinelli (2002) found that city-aggregate and metropolitan areas with a higher percentage of college graduates grew faster over the 20th century in the U.S.. Shapiro (2003) used the 1940, 1970, 1980, and 1990 Integrated Public Use Microdata Series (IPUMS) databases and concluded that the deepening of human capital contributes to the growth of urban employment, wages, and housing value. In his overall sample, a $10 \%$ increase in the share of college educated residents generated a $0.2 \%$, $0.6 \%$, and $0.7 \%$ increase in wage, urban employment, and housing value growth, respectively. It is in this sense that he called cities, "Smart."

\subsection{Marshallian Labor Market Externalities}

The original idea of human capital externalities probably first dates back to Alfred Marshall (1920). Marshall emphasized that human capital externalities take place mostly between workers in the same industry and city through faceto-face interactions. He also stressed technological spillovers from one firm to another firm nearby in the same industry in a city. He defined the benefits a firm obtains from the general development of the industry as external economies (1920, p.266). It is within this dynamic context, recently, urban economists developed the concept, "Marshallian externalities," meaning firms can benefit from the concentration of same-industry firms in an intertemporal context (Glaser, et al., 1992). ${ }^{4}$ Empirical works have identified that Marshallian externalities are significant in many industries. For example, Henderson (2003) found that

\footnotetext{
${ }^{4}$ In urban literature, economies external to firms but internal to the industry are dubbed "localization economies" in static context; in this case, individual firms benefit from the local concentration of same-industry firms. Economies external to industries but internal to a city are called urbanization economies; here individual firms benefit from the concentration of different industries in a city. Informally speaking, dynamic localization economies are called Marshallian or Marshall-Arrow-Romer externalities, and dynamic urbanization economies are called Jacobs externalities. One of the main sources of dynamic externalities is the accumulation of different types of human capital.
} 
Marshallian externalities have strong productivity effects in high-tech industries.

We hypothesize that workers can learn from the local concentration of sameoccupation and same-industry peers. We refer to this "Marshallian labor market externalities." The mechanism is such that the concentration of specialized skilled workers generates more competition, which provides a strong motivation for workers to learn the most up-to-date knowledge and speeds the creation and diffusion of new knowledge. This is the crucial point of Porter's theory of competitive advantage in regional clusters (Porter, 1990; 1998). Also, increased division of labor generates comparative advantage compared with under-specialized regions.

We use the degree of occupation (industry) specialization at a location to measure Marshallian labor market externalities. The occupation (industry) specialization index is the ratio of the employment in a certain occupation (industry) at a location to the total employment at that location. This index measures the intensity and frequency of social interactions and knowledge spillovers among same-occupation (same industry) workers at a location. Wheaton and Lewis (2002) were probably the first to test Marshallian labor market externalities. They used manufacturing industry wage data from the 5\% Public Use Micro Sample (PUMS) of the 1990 U.S. census, and found that the differences in occupation specialization and industry specialization across MSAs could generate $23 \%$ and $30 \%$ higher wages, respectively.

\subsection{Jacobs Labor Market Externalities}

Jacobs (1969), with many concrete examples, emphasized that it is the variety and diversity of geographically proximate industries that promote innovation and city growth. This is why the benefits from urban diversity in the dynamic context are called, "Jacobs externalities." Firms benefit from urban diversity due to the following external economies: shared inputs, lower transaction costs, and statistical economies of scale in production and consumption. Examples would be business services and consumption amenities, labor market matching and shopping districts, and unemployment insurance in a diverse labor market 
(Quigley, 1998; Duranton and Puga, 2000). New economic geography models (Fujita, et al., 1999) and some endogenous growth models (Barro and Sala-IMartin, 1995, chapter 6) show that diversity and variety in producer inputs or consumption goods can generate external scale economies.

The empirical results of testing Jacobs externalities are mixed. Glaeser et al. (1992) concluded that urban diversity encourages employment growth in industries, while Henderson (2003) found little evidence of Jacobs externalities in the high-tech and machinery industries.

Workers benefit from the diversity of labor markets, which we call, "Jacobs labor market externalities." One reason is that many inventions are interdisciplinary due to the stimulation of "ideas" in heterogeneous surroundings in cities. Berliant et al. (2002) assumed that individuals possess horizontally differentiated types of knowledge and randomly search for partners with whom to exchange ideas in order to improve production efficacy. Their model shows that the addition of new knowledge through matching results in endogenous growth.

A second reason is that labor market diversity reflects an open and tolerant social and cultural milieu that attracts different types of talented people to that area. Florida (2002) constructed a bohemia index - the bohemian population at the MSA level and found that the presence and concentration of bohemians is highly correlated with the concentration of high human capital individuals and innovative high-tech industries. ${ }^{5}$ In another paper (Florida, 2000), he found that the geographic distribution of talent is closely associated with diversity (meaning low entry barriers) and urban amenities.

We construct an occupation (industry) diversity index that equals one minus the Herfindahl index. The Herfindahl index is the sum of squared shares of employment of different occupations (industries) at a location. It is possible that the spatial concentration of different industries may imply scale economies from forward or backward linkages, but other indices such as inputs or volume of shipments are a better measurement. Our diversity indices are based on the

\footnotetext{
${ }^{5}$ Florida's selection of bohemian occupations included: authors; designers, musicians and composers; actors and directors; craft-artists, painters, sculptors, and artist printmakers; photographers; dancers; artists, performers, and related workers.
} 
number of employees in different occupations and industries, which measure the broadness and horizontal differences of human capital stock in a local labor market. To the best of our knowledge, this paper is the first to test the effects of labor market diversity on individual earnings.

\subsection{The Thickness of Labor Market}

The more densely concentrated a labor market in a limited geographic area, the more luck workers will have in their random matches, that is, workers benefit from the thickness or density of a local labor market. In the literature, labor market pooling (from the viewpoint of firms) sometimes also means the thickness of labor market, though it is used to explain both localization and urbanization economies. The importance of labor market thickness at microgeographic levels is that workers can socialize more frequently and build social networks more easily to exchange information. Bayer et al. (2004) detected that social interactions among block neighbors help workers to build informal hiring networks, which have a significant impact on a wide range of labor market outcomes.

Employment density, the number of workers per square kilometers, is a simple index for gauging the thickness of a local labor market. An alterative is an occupation (industry) concentration index, which is the ratio of employment of an occupation (industry) at a location to the total employment of that occupation (industry) over all the locations. However, the values of concentration indices depend on the specification of geographic units.

In a labor market with imperfect information, firms and workers search for each other to form an idea match. The larger or more dense a labor market is, the higher the probability of a better match between jobs and workers with heterogeneous human capital. This labor market pooling effect can generate agglomeration economies even without learning behavior (Helsley and Strange, 1990). Ciccone and Hall (1996) were the first to put density of economic activity into theory and empirical test. Their models show that spatial density results in aggregate increasing returns: a doubling of employment density in a county results in a $6 \%$ increase of average labor productivity. These locally increasing 
returns can explain more than half of the variance of output per worker across the United States. Wheaton and Lewis (2002) found that the differences in occupation and industry concentration across MSAs could generate $12 \%$ and $16 \%$ higher wages, respectively.

\section{The Geographic Scope of Human Capital Ex- ternalities}

The flow of knowledge across geographic space is costly. Information spillovers which require frequent contact between workers may dissipate over a short distance, since walking to a meeting place becomes more difficult, or random encounters become more rare, in a far away and less dense area. But what is the exact spatial scale where human capital externalities take place? How fast do knowledge spillovers decay spatially? These are empirical questions.

Most empirical works on agglomeration economies have used aggregate data, taking countries, states, MSAs, cities, or counties as geographic units. Rosenthal and Strange (2003a) used zip code level firm data and studied six industries. In most industries, same industry employment encourages the number of births per square mile and new establishment employment per square mile. They interpreted this as evidence of significant localization economies. They found that localization economies attenuate with distance: the initial attenuation is rapid, with the effect of own-industry employment in the first mile away from zip code centroid up to 10 to 1000 times larger than the effect two to five miles away; beyond five miles, attenuation is much slower. Duranton and Overman (2002) also found that business agglomeration effects are very localized (at zip code level) and decay fast with distance.

As for knowledge spillovers, Lucas (1988) argued that metropolitan areas are the most appropriate units to examine when looking for the productivityenhancing effects of human capital abundance. Rauch (1993) found evidence on human capital externalities at the SMSA level. Simon and Nardinelli (2002) argued that knowledge spillovers are geographically limited to the city and much 
knowledge is most productive in the city within which it is acquired. They found that the estimated effects of human capital on employment growth are very large at the city-aggregate level, but smaller on metropolitan areas. Wheaton and Lewis (2002) tested Marshallian externalities and the effect of local labor market thickness at the MSA or Consolidated Metropolitan Statistical Area (CMSA) level. Beeson, Delong, and Troesken (1999) identified human capital infrastructure as a determinant of population growth at county level over the period 1840-1990.

No work has been done to identify the microgeographic scope of human capital externalities. ${ }^{6}$ In this paper, we make a contribution to this unexplored topic. We construct labor market attribute indices at the census tract, blockgroup, and block level, and estimate hedonic wage models with different location fixed effects. We find that all of the proposed four types of human capital externalities are strong and significant across tracts and even across blocks. Marshallian labor market externalities and the effect of industry employment density are significant at the block level. We also find that the effects of human capital externalities attenuate at different speeds with distance away from block centroid. It is in this sense that we call cities, "Café Cities."

\section{Model Specification and Identification}

In this section we specify two types of models and discuss the identification strategies. The first is a benchmark model for testing the magnitude and significance of the types of human capital externalities at different spatial scales. The second is constructed to detect the spatial decay patterns of those externalities.

\subsection{The Benchmark Model}

The benchmark model is specified as an augmented hedonic wage model including both individual characteristics and local labor market attributes. The labor

\footnotetext{
${ }^{6}$ Literature on "neighborhood effects" studied social interactions at different geographical levels. Bayer et al. (2004) detected social interaction (informal hiring referral) between workers at the census block level.
} 
market attribute indices are constructed at the census tract level.

$$
\log W_{n o i j}=\alpha+\lambda_{c}+\beta^{\prime} X_{n}+\gamma^{\prime} X_{j}+\epsilon_{n o i j}
$$

where $W_{n o i j}$ is the hourly wage of worker $n$, whose occupation is $o$ and who worked in industry $i$ at census tract $j, \alpha$ is a constant, $\lambda_{c}$ is county fixed effects, $X_{n}$ is the characteristics vector of worker $n, X_{j}$ is the attributes vector of local labor market at census tract $j, \beta$ and $\gamma$ are the coefficient vectors to be estimated, and $\epsilon_{\text {noij }}$ is the error term. ${ }^{7}$

Variables of individual characteristics include age, age square (proxy for working experience), dummy variables for gender, marriage, race, education, English proficiency, student, veteran, and working disability. Industry and occupation dummies are also included to control for industry and occupation specific effects. Since commuting costs must be capitalized into wages if firms are located at different points within a metropolitan area, we also include commuting time (minutes) to the workplace in the model.

Local labor market attributes include indices for human capital depth of local labor market and of each occupation and industry, occupation specialization, occupation diversity, occupation employment density, industry specialization, industry diversity, and industry employment density. Variables for these indices are constructed as follows:

AveEdu: percentage of college or higher degree-holders among all the workers at tract $j$, representing the overall depth of human capital stock at tract $j$.

AveEduOcc: percentage of college or higher degree-holders among all the workers of occupation $o$ at tract $j$, representing the depth of human capital stock for occupation $o$ employment at tract $j$.

AveEduInd: percentage of college or higher degree-holders among all the workers in industry $i$ at tract $j$, representing the depth of human capital stock for industry $i$ employment at tract $j$.

\footnotetext{
${ }^{7}$ Census tracts are nested within counties. The Boston Metropolitan Area (BMA) includes all of Suffolk county, and portions of 6 other counties: Bristol, Essex, Middlesex, Norfolk, Plymouth, and Worcester county.
} 
OccSpec: occupation specialization index for workers of occupation $o$ at tract $j$. It is the ratio of the number of workers of occupation $o$ at tract $j$ to the total number of workers at that tract, used to proxy for Marshallian labor market externalities among occupational peers.

OccDiver: occupation diversity index for workers at tract $j$. It equals one minus the Herfindahl index, representing Jacobs labor market externalities in terms of occupation diversity. Let $S_{o j}$ denote the ratio of occupation $o$ employment at tract $j$ to the total employment at tract $j$, then the occupation diversity index

$$
\text { OccDiver }=1-\sum_{o} S_{o j}^{2}
$$

Note that if there is only one occupation in a tract, the Herfindahl index equals 1 , and the diversity index equals 0 ; if there are many occupations in a tract, and the share of employment in each occupation is very small, then the Herfindahl index is close to 0 , and the occupation diversity index becomes close to 1. The larger the value of the occupation diversity index, the more diverse the local labor market is, in term of occupations.

OccDens: occupation employment density index for workers of occupation $o$ at tract $j$. It equals the number of workers of occupation $o$ per square kilometers at tract $j$, and is used to measure the thickness of a local labor market in terms of occupation o employment. We do not use occupation concentration index as Wheaton and Lewis (2002) did because it is geographic-variant.

The same methods are applied to the construction of industry indices. For example: the industry specialization index would be

$$
\text { IndSpec }=\frac{\text { number of workers in industry } i \text { at tract } j}{\text { total employment at tract } j} .
$$

The industry diversity index

$$
\text { IndDiver }=1-\sum_{i} S_{i j}^{2}
$$

where $S_{i j}$ denotes the ratio of employment in industry $i$ at tract $j$ to the total employment at tract $j$. 
IndDens: industry employment density index for workers in industry $i$ at tract $j$. It is the number of industry $i$ workers per square kilometers at tract $j$.

We estimate model (1) by pooling all the data, and by occupation and industry. The results are reported in sections 6.1 and 6.2 .

\subsection{Identification Strategies}

The error term captures the effects of unobservable locational attributes, unobservable individual characteristics, and measurement errors. Most likely the error terms are spatially correlated and are not identically and independently distributed. In this subsection we discuss how to deal with these problems.

A location may have better accessibility, or other natural or historical advantages, which are omitted in model (1). We use location fixed effects to capture the omitted locational attributes. For example, in model (1) the county fixed effects control for county specific attributes; therefore, we can identify the significance of all types of human capital externalities within a county or across tracts. However, unobservable tract specific attributes may affect our estimation. To identify what types of human capital externalities are significant within tracts, we estimate model (1) with tract fixed effects, but we have to drop variables AveEdu, OccDiver, and IndDiver, since they are invariant within each

tract. By the same token, to identify what types of human capital externalities are significant across (within) census blocks, we construct the labor market attribute indices at the census block level, and estimate a model with blockgroup (block) fixed effects.

Workers may have unobservable characteristics or intrinsic preferences, which correlate with the independent variables in model (1). For example, workers with high-level human capital may strongly prefer to work in a place where well-educated workers concentrate, even though no learning externalities occur. This sorting effect causes the correlation between the error terms and some labor market attribute indices. This endogeneity problem is hard to overcome in cross-section models. We leave this for future research.

Locations nearby may share some common attributes, such as infrastruc- 
tures, economic policy, and complementary industries. This causes spatial autocorrelation between error terms. Within each location, error terms may not be identically and independently distributed. We address this issue in two ways. First we use location fixed effects to control for the correlation between locations; second, to deal with heteroscedasticity and autocorrelation within each location, we use the Huber/White estimate of variance clustered by locations to produce consistent standard errors. ${ }^{8}$ However, there is no theoretical guarantee to believe that the locations classified by the Census Bureau are the perfect controls. The better alternative may be to use non-parametric or semi-parametric estimates, or spatial econometric methods by using spatial weights (Gibbson and Machin, 2003; Anselin, 1988). We leave this on the future agenda.

No matter how carefully designed and implemented, the census data still contain measurement errors, such as undercount. The measurement error problem will be magnified when using data at lower geographic levels, but less serious at aggregate levels or locations with large observations. Measurement errors in dependent variables will cause the coefficients to be underestimated. We will take this into account when we interpret estimate results from lower geographical models. We also estimate models by selecting locations where the number of workers is greater than a certain number to get a sense of measurement errors.

Some indices are moderately correlated (See Table A-5 in the appendix), which hints that our proposed human capital externalities percolation channels may interact with each other. For example, high diversity may attract highlyeducated workers; high occupation diversity may imply low specialization for some occupations; a high degree of specialization of some occupations in downtown may also imply high occupation employment density. However, in this study we do not consider the interaction problem since we are particularly interested in identifying the different dimensions of human capital externalities. Our huge sample size can reduce the standard errors and partly remedy the collinearity problem.

\footnotetext{
${ }^{8}$ We use the STATA command "areg" with option "cluster", which allows that the residuals are not identically distributed and are not independent within clusters.
} 


\subsection{The Spatial Attenuation Model}

To test how human capital externalities attenuate with distance, we adopt the methodology proposed by Rosenthal and Strange (2003a). For each block, we construct concentric rings of various radii away from the centroid of that block; for every ring, we construct the seven indices of labor market attributes, respectively, based on the employment in that ring. ${ }^{9}$ We then estimate model (1) by replacing $X_{j}$ with all the indices for each ring.

Given that the census data provide individual residential and working address information only down to block level, we cannot precisely compute distances between any two workers. To compute the distance between any two block centroids, we assume that all employment in a block concentrates at the centroid of that block. If a block centroid is within a particular ring, then the whole area of that block is considered in that ring, too.

The alternative is to assume that employment is uniformly distributed at each block, then construct rings of certain miles away from block centroid. In order to infer the proportion of employment from each overlapped block in a ring, Geographical Information Systems (GIS) software is needed to compute areas of all the parts of blocks that overlap with that ring. However, in our sample, each worker has a set of heterogeneous characteristics in terms of education, race, occupation, and industry. Even if we assume that workers are uniformly distributed within blocks, we still cannot guarantee that workers of a certain characteristic are also uniformly distributed. Therefore, it is impossible to construct all indices for each ring in a consistent way. Rosenthal and Strange (2003a) adopted the uniform distribution assumption because their variables were not individual specific. Compared to metropolitan areas, it does not make much difference whether one assumes that workers are uniformly distributed within a block or concentrate at block centroid. ${ }^{10}$

\footnotetext{
${ }^{9}$ Here we only use $A v e E d u$ to measure human capital depth. The inclusion of $A v e E d u O c c$ and AveEduInd does not change results much, but makes the presentation harder since we already have too many variables.

${ }^{10}$ Actually, Rosenthal and Strange also estimated their models by assuming employment concentrate at the centroid of each zip code area. The results are very similar.
} 
The results of our spatial attenuation model are reported in section 6.3.

\section{Data}

We use the restricted version of the 1990 Massachusetts census data. The data set contains detailed information on surveyed individuals' personal characteristics, family structure, geography information of residential and working place, and housing characteristics. The sample we use in this paper is constructed as follows: select workers ages 16-65, working in the Boston metropolitan area, who reported non-zero wages, their hours usually worked per week, and their weeks worked in the previous year. We exclude workers whose industry was agriculture, mining, military, or not classified, and also exclude workers who have disabilities preventing them from working. For the tract level model, we select only tracts where the number of workers is greater than $1 .{ }^{11}$ We apply the same rule for blockgroup and block level models. The tract level model sample includes 150,952 observations, 7 counties, 621 census tracts, 2,461 blockgroups, and 11,395 blocks. Some summary statistics are listed in Table A-1 in the appendix. Tables A-2 and A-3 list the industries and occupations we classify in this paper. Table A-4 presents the mean and standard deviations across tracts for all the tract-level labor market attribute indices for some selected occupations and industries. Table A-5 presents the correlation matrix for all the labor market attribute indices.

\section{Results}

\subsection{Benchmark model results}

We first estimate model (1) with county and tract fixed effects. The results are reported in Table 1.

\footnotetext{
${ }^{11}$ If there is only one worker in a location, there is no social interaction in that local labor market. We also estimate models including those locations and the results are very similar.
} 
TABLE 1

Benchmark Model at the Tract Level

\begin{tabular}{|c|c|c|c|c|}
\hline \multicolumn{5}{|c|}{$\begin{array}{c}\text { Fixed effects regression with clustered standard errors } \\
\text { Dependent Variable: } \log (\text { imputed hourly wage); total observations: } 150952\end{array}$} \\
\hline \multirow[b]{2}{*}{ Independent Variable } & \multicolumn{2}{|c|}{ County fixed effects } & \multicolumn{2}{|c|}{ Tract fixed effects } \\
\hline & Coefficient & Std. error & Coefficient & Std. error \\
\hline Constant & 0.9903 & 0.1285 & 1.4917 & 0.0392 \\
\hline Single dummy & -0.2015 & 0.0046 & -0.2003 & 0.0054 \\
\hline Female dummy & -0.2140 & 0.0276 & -0.2106 & 0.0109 \\
\hline Single*female & 0.2283 & 0.0169 & 0.2266 & 0.0062 \\
\hline Age & 0.0508 & 0.0021 & 0.0506 & 0.0013 \\
\hline $\mathrm{Age}^{2}$ & -0.0005 & 0.0000 & -0.0005 & 0.0000 \\
\hline White dummy & 0.1805 & 0.0129 & 0.1815 & 0.0084 \\
\hline White*female & -0.1213 & 0.0034 & -0.1230 & 0.0100 \\
\hline Student dummy & -0.0745 & 0.0057 & -0.0718 & 0.0068 \\
\hline Veteran dummy & 0.0600 & 0.0156 & 0.0600 & 0.0057 \\
\hline Disability dummy & -0.1480 & 0.0028 & -0.1469 & 0.0101 \\
\hline College dummy & 0.1429 & 0.0028 & 0.1441 & 0.0038 \\
\hline Graduate dummy & 0.2807 & 0.0032 & 0.2825 & 0.0097 \\
\hline English proficiency dummy & -0.0480 & 0.0021 & -0.0448 & 0.0057 \\
\hline Commuting time & 0.0017 & 0.0001 & 0.0016 & 0.0001 \\
\hline Average education (\%) & 0.1535 & 0.0149 & & \\
\hline Av. Edu. occupation (\%) & 0.0474 & 0.0183 & 0.0496 & 0.0191 \\
\hline Av. Edu. industry (\%) & 0.0399 & 0.0189 & $\{0.0251\}$ & 0.0167 \\
\hline Occ. specialization (\%) & 0.1697 & 0.0231 & 0.2025 & 0.0504 \\
\hline Ind. specialization (\%) & 0.0643 & 0.0103 & 0.0523 & 0.0178 \\
\hline Occ. diversity $(\%)$ & 0.2986 & 0.1107 & & \\
\hline Ind. diversity (\%) & 0.2116 & 0.0201 & & \\
\hline Occ. employment density & $\{0.0035\}$ & 0.0022 & $\{-0.0099\}$ & 0.0083 \\
\hline Ind. employment density & 0.0374 & 0.0054 & 0.0419 & 0.0095 \\
\hline$R^{2}$ & \multicolumn{2}{|c|}{0.326} & \multicolumn{2}{|c|}{0.333} \\
\hline S.E. clusters & \multicolumn{2}{|c|}{$\operatorname{county}(7)$} & \multicolumn{2}{|c|}{ tract $(621)$} \\
\hline
\end{tabular}

Note: \{\} indicates insignificance at the $5 \%$ level.

Occupation and industry dummies are included.

In Table 1, the county fixed effects model shows that estimated coefficients for all the variables of individual characteristics and local labor market attributes are significant at the $5 \%$ level except that the coefficient of occupation employment density index is significant at the $10 \%$ level. The effects of human capital depth at the tract level are decomposed into three components: the depth of overall, same-occupation, and same-industry human capital stock. The coefficient of AveEdu shows that a $1 \%$ increase in the share of workers who 
are college graduates in a tract increases workers' hourly wage at that tract on average by $0.15 \%$; a one standard deviation of AveEdu (0.126) generates wage growth effects of $1.89 \%$ across tracts. The effects of human capital depth of occupational and industrial peers are smaller, the elasticity is about 0.05 and 0.04 .

The Marshallian labor market externalities reflected by the occupation specialization index are stronger than the effects of overall human capital depth, the elasticity is about 0.17 . The Jacobs externalities, indicated by the occupation and industry diversity variables, are strong. One standard deviation increase in occupation diversity $(0.057)$ across tracts generates a $1.71 \%$ increase in hourly wages; a one standard deviation in industry diversity (0.105) generates $2.21 \%$ higher hourly wages. The effects of labor market thickness in terms of industrial employment density are very strong, adding one more same-industry worker to a square kilometer area at a tract generates 3.7\% wage growth. Note that we controlled for individual characteristics, county, industry, and occupation specific effects; our results reflect the very general effects of human capital externalities across heterogeneous workers within a county.

To test the stability of the model specification, we also estimate a series of models slightly different from the benchmark model. For example, drop the occupation dummies, industry dummies, or diversity indices, and select only workers in non-government sectors, and select only tracts where the number of workers is greater than 100 or 200. The coefficients are somewhat different, but, the overall patterns are pretty similar (results are not reported here). The presented model is our preferred specification.

The county fixed effects model shows that, within a county, all the types of labor market externalities (except occupation employment density) are significant at the $5 \%$ level. To identify what types of externalities are significant at the tract level, we drop AveEdu and diversity indices and estimate a tract fixed effects model. The results in Table 1 show that the quality of human capital in an occupation, Marshallian labor market externalities, and industry employment density are significant at the tract level. 
To identify what types of human capital externalities are significant at lower geographical levels, we construct the labor market attribute indices at the blockgroup and block level. For example, in the block level model, the overall depth of human capital is the percentage of workers who are college graduates at a block; the occupation specialization index is the ratio of same-occupation workers at a block to the total number of workers at that block. We then estimate the benchmark model at the blockgroup and block level with different locational fixed effects respectively. Tables 2 and 3 present the results for blockgroup and block level models, where only the labor market attribute indices are listed.

TABLE 2

Benchmark Model at the Blockgroup Level

\begin{tabular}{lcccccc}
\hline \hline Fixed effects & \multicolumn{2}{c}{ County } & \multicolumn{2}{c}{ Tract } & \multicolumn{2}{c}{ Blockgroup } \\
\hline Variable & Coefficient & Std.error & Coefficient & Std. error & Coefficient & Std.error \\
\hline AveEdu & 0.1174 & 0.0157 & $\{0.0053\}$ & 0.0278 & & \\
AveEduOcc & $\{0.0222\}$ & 0.0159 & 0.0252 & 0.0130 & 0.0245 & 0.0124 \\
AveEduInd & 0.0224 & 0.0076 & $\{0.0127\}$ & 0.0121 & $\{0.0099\}$ & 0.0121 \\
OccSpec & 0.1142 & 0.0428 & 0.1385 & 0.0333 & 0.1452 & 0.0312 \\
IndSpec & 0.0642 & 0.0086 & 0.0563 & 0.0146 & 0.0554 & 0.0160 \\
OccDiver & 0.1843 & 0.0442 & 0.2004 & 0.0669 & & \\
IndDiver & 0.1390 & 0.0136 & $\{0.0264\}$ & 0.0279 & & -0.0089 \\
OccDens & 0.0062 & 0.0024 & $\{-0.0070\}$ & 0.0070 & 0.0041 \\
IndDens & 0.0159 & 0.0039 & 0.0186 & 0.0040 & 0.0183 & 0.0059 \\
\hline$R^{2}$ & 0.326 & 0.333 & & 0.345 & \\
S.E. clusters & County $(7)$ & Tract $(620)$ & Blockgroup $(2351)$ \\
\hline \hline
\end{tabular}

Note: \{\} indicates insignificance at the $5 \%$ level.

All indices are constructed at the blockgroup level.

In Table 2, the blockgroup fixed effects model identifies the types of externalities that are significant within a blockgroup, including the quality of human capital among same-occupation peers, Marshallian labor market externalities, and the thickness of the labor market. 
TABLE 3

Benchmark Model at the Block Level

\begin{tabular}{lcccc}
\hline \hline Fixed effects & County & Tract & Blockgroup & Block \\
\hline Variable & Coefficient & Coefficient & Coefficient & Coefficient \\
\hline AveEdu & 0.0889 & 0.0414 & 0.0383 & \\
AveEduOcc & 0.0059 & 0.0160 & 0.0180 & \\
& $\{0.0114\}$ & $\{0.0127\}$ & $\{0.0125\}$ & $\{0.0063\}$ \\
AveEduInd & 0.0101 & 0.0091 & 0.0091 & 0.0095 \\
& $\{-0.0026\}$ & $\{-0.0102\}$ & $\{-0.0117\}$ & $\{-0.0108\}$ \\
OccSpec & 0.0057 & 0.0086 & 0.0092 & 0.0097 \\
& 0.0545 & 0.0643 & 0.0661 & 0.0891 \\
IndSpec & 0.0197 & 0.0194 & 0.0196 & 0.0206 \\
& 0.0670 & 0.0603 & 0.0614 & 0.0590 \\
OccDiver & 0.0068 & 0.0120 & 0.0124 & 0.0120 \\
& 0.1428 & 0.1462 & 0.1451 & \\
IndDiver & 0.0205 & 0.0319 & 0.0317 & \\
& 0.0860 & 0.0372 & 0.0442 & \\
OccDens & 0.0174 & 0.0175 & 0.0190 & $\{0.0017\}$ \\
IndDens & 0.0064 & 0.0039 & 0.0036 & 0.0016 \\
& 0.0001 & 0.0011 & 0.0016 & 0.0024 \\
\hline$R^{2}$ & 0.0026 & 0.0031 & 0.0028 & 0.0011 \\
S.E. clusters & 0.0010 & 0.0011 & 0.0012 & 0.385 \\
\hline \hline
\end{tabular}

Note: \{\} indicates insignificance at the $5 \%$ level. Standard errors are in the rows below the coefficients. All indices are constructed at the block level.

In Table 3, the blockgroup fixed effects model shows that almost all types of human capital externalities are significant across blocks. The block fixed effects model further identifies that Marshallian labor market externalities and labor market thickness in terms of industrial employment are significant at the block level.

Table 4 further summarizes different types of human capital externalities that are significant at the $5 \%$ percent level at different geographic scopes. 
TABLE 4

Different Types of Externalities Significant at Different Geographic Levels

\begin{tabular}{lcccccc}
\hline \hline & $\begin{array}{c}\text { Across } \\
\text { Tracts }\end{array}$ & $\begin{array}{l}\text { Within } \\
\text { Tract }\end{array}$ & $\begin{array}{l}\text { Across } \\
\text { Blockgroups }\end{array}$ & $\begin{array}{l}\text { Within } \\
\text { Blockgroup }\end{array}$ & $\begin{array}{l}\text { Across } \\
\text { Blocks }\end{array}$ & $\begin{array}{l}\text { Within } \\
\text { Block }\end{array}$ \\
\hline AveEdu & $\mathrm{Y}$ & & & & $\mathrm{Y}$ & \\
AveEduOcc & $\mathrm{Y}$ & $\mathrm{Y}$ & $\mathrm{Y}$ & $\mathrm{Y}$ & & \\
AveEduInd & $\mathrm{Y}$ & & & & & \\
OccSpec & $\mathrm{Y}$ & $\mathrm{Y}$ & $\mathrm{Y}$ & $\mathrm{Y}$ & $\mathrm{Y}$ & $\mathrm{Y}$ \\
IndSpec & $\mathrm{Y}$ & $\mathrm{Y}$ & $\mathrm{Y}$ & $\mathrm{Y}$ & $\mathrm{Y}$ & $\mathrm{Y}$ \\
OccDiver & $\mathrm{Y}$ & & $\mathrm{Y}$ & & $\mathrm{Y}$ & \\
IndDiver & $\mathrm{Y}$ & & & & $\mathrm{Y}$ & \\
OccDens & & & & & $\mathrm{Y}$ & \\
IndDens & $\mathrm{Y}$ & $\mathrm{Y}$ & $\mathrm{Y}$ & $\mathrm{Y}$ & $\mathrm{Y}$ & $\mathrm{Y}$ \\
\hline \hline
\end{tabular}

The most striking result in Table 4 is that the Marshallian labor market externalities are significant at all microgeographic levels, including at the block level. Almost all types of externalities are significant across blocks, as well as across tracts. It is in this sense that we call cities, "Café Cities."

In Table 5, we assemble the results from the benchmark model at the tract, blockgroup, and block levels, where only county fixed effects are included.

TABLE 5

Benchmark Model at Different Microgeographic Levels

\begin{tabular}{lcccc}
\hline \hline & Tract level & Blockgroup Level & \multicolumn{2}{c}{ Block Level } \\
\cline { 2 - 5 } & $N>1$ & $N>1$ & $N>1$ & $N>10$ \\
\hline & Coefficient & Coefficient & Coefficient & Coefficient \\
\hline AveEdu & 0.1535 & 0.1174 & 0.0889 & 0.1371 \\
AveEduOcc & 0.0474 & $\{0.0222\}$ & $\{0.0114\}$ & 0.0256 \\
AveEduInd & 0.0399 & 0.0224 & $\{-0.0026\}$ & 0.0186 \\
OccSpec & 0.1697 & 0.1142 & 0.0545 & 0.0880 \\
IndSpec & 0.0643 & 0.0642 & 0.0670 & 0.0612 \\
OccDiver & 0.2986 & 0.1843 & 0.1428 & $\{0.0246\}$ \\
IndDiver & 0.2116 & 0.1390 & 0.0860 & 0.1041 \\
OccDens & $\{0.0035\}$ & 0.0062 & 0.0064 & 0.0054 \\
IndDens & 0.0374 & 0.0159 & 0.0026 & 0.0023 \\
\hline \hline
\end{tabular}

Note: $\{$ \} indicates insignificance at the $5 \%$ level. All models include county fixed effects. $N$ is the number of workers at a location.

Table 5 shows some interesting spatial patterns of human capital externalities. The coefficients of occupation employment density are increasing when moved down to the lower geographic levels, which hints that they decay with 
distance away from a block. The coefficients of industrial Marshallian externalities are very similar, which hints that they decay very slowly within a tract. All other indices have the same pattern: much stronger at the tract level, much smaller at the block level. The explanation could be as follows: these externalities are strong at the tract level, but measurement errors attenuate the coefficients at the blockgroup and block level. To test this hypothesis, we estimate the block level model by selecting only blocks where the number of workers is greater than 10. The results show that most of the coefficients, indeed, increase significantly. Tentatively, we conclude that, without measurement errors, the coefficients of human capital depth, occupation specialization, diversity indices, and industry employment density would be similar at the tract, blockgroup, and block level.

The above rough spatial patterns indicate that different types of human capital externalities take place at different geographic scopes, and attenuate spatially at different speeds. However, we cannot see the pattern beyond the tract level. The natural extension is to test the spatial decay patterns of different types of human capital externalities within a larger geographic scope.

\subsection{Human Capital Externalities by Occupation and In- dustry}

We also estimate model (1) by occupation and industry to explore the human capital externalities within a labor market of a particular occupation or industry at the tract level. Table 6 presents the results for a few selected occupations and industries. 
TABLE 6

Benchmark Model by Industry and Occupation

\begin{tabular}{|c|c|c|c|c|c|c|}
\hline & \multicolumn{2}{|c|}{ High-tech } & \multicolumn{2}{|c|}{ Computer } & \multicolumn{2}{|c|}{ Manufacturing } \\
\hline & Coefficient & Std. error & Coefficient & Std.error & Coefficient & Std. error \\
\hline AveEdu & 0.3351 & 0.0890 & 0.3258 & 0.1663 & 0.2901 & 0.0562 \\
\hline AveEduOcc & $\{-0.0289\}$ & 0.0577 & 0.0786 & 0.0176 & $\{0.0270\}$ & 0.0282 \\
\hline AveEduInd & $\{0.0527\}$ & 0.0469 & $\{0.0125\}$ & 0.0860 & $\{0.0107\}$ & 0.0652 \\
\hline OccSpec & 0.3996 & 0.0914 & $\{0.0341\}$ & 0.0933 & $\{0.1664\}$ & 0.0870 \\
\hline IndSpec & 0.1527 & 0.0161 & 0.5942 & 0.2181 & 0.2243 & 0.0555 \\
\hline OccDiver & $\{0.1122\}$ & 0.2924 & $\{0.6238\}$ & 0.7001 & $\{0.2649\}$ & 0.3615 \\
\hline IndDiver & 0.1345 & 0.0474 & 0.2644 & 0.0999 & 0.1470 & 0.0463 \\
\hline OccDens & $\{-0.0245\}$ & 0.0654 & -0.0418 & 0.0150 & -0.0229 & 0.0094 \\
\hline IndDens & $\{-0.0370\}$ & 0.1104 & $\{-0.0642\}$ & 0.1530 & $\{0.1019\}$ & 0.0597 \\
\hline Observations & 6251 & & 2139 & & 21861 & \\
\hline \multirow[t]{3}{*}{$R^{2}$} & 0.449 & & 0.312 & & 0.404 & \\
\hline & \multicolumn{2}{|c|}{$\begin{array}{c}\text { Writers,artists } \\
\text { entertainers, athletes }\end{array}$} & \multicolumn{2}{|c|}{$\begin{array}{c}\text { Mathematical } \\
\text { computer scientists }\end{array}$} & \multicolumn{2}{|c|}{$\begin{array}{c}\text { Managerial } \\
\text { professional specialty }\end{array}$} \\
\hline & Coefficient & Std. error & Coefficient & Std. error & Coefficient & Std. error \\
\hline AveEdu & 0.4819 & 0.0832 & $\{0.0029\}$ & 0.1338 & $\{0.0939\}$ & 0.0779 \\
\hline AveEduOcc & $\{0.0377\}$ & 0.0601 & 0.1560 & 0.0606 & 0.0973 & 0.0143 \\
\hline AveEduInd & $\{-0.0967\}$ & 0.2279 & $\{0.1427\}$ & 0.1221 & 0.0619 & 0.0258 \\
\hline OccSpec & $\{-0.0826\}$ & 0.3485 & 1.6416 & 0.2682 & 0.3491 & 0.0901 \\
\hline IndSpec & $\{0.2933\}$ & 0.1922 & $\{0.0385\}$ & 0.0624 & 0.0907 & 0.0343 \\
\hline OccDiver & 1.6508 & 0.3804 & $\{0.2300\}$ & 0.3002 & $\{-0.0021\}$ & 0.1950 \\
\hline IndDiver & 0.4721 & 0.1708 & 0.2166 & 0.0400 & 0.2524 & 0.0673 \\
\hline OccDens & 0.3441 & 0.0955 & $\{0.4985\}$ & 0.3254 & 0.0086 & 0.0032 \\
\hline IndDens & $\{0.0140\}$ & 0.0232 & -0.0704 & 0.0219 & 0.0381 & 0.0065 \\
\hline Observations & 3400 & & 2177 & & 26287 & \\
\hline$R^{2}$ & 0.172 & & 0.223 & & 0.292 & \\
\hline
\end{tabular}

Note: \{\} indicates insignificance at the $5 \%$ level. Individual variables, occupation or industry dummies, and county fixed effects are included.

Table 6 shows that high-tech industry workers benefit strongly from Marshallian labor market externalities, which is consistent with Henderson's finding based on plant level data. Manufacturing industry workers benefit from both Marshallian and Jacobs externalities, which is consistent with the literature on dynamic externalities. The same pattern holds for computer industry workers. Management occupation workers benefit from all of the four types of human capital externalities by different degrees. Computer scientists benefit strongly from same-occupation peers and industrial diversity. Artists strongly benefit from urban diversity, which is very consistent with Florida's argument based on 
his bohemian index. In brief, channels of knowledge spillovers vary in sub-labor markets of different occupations and industries.

\subsection{Spatial Attenuation Model Results}

We construct all the labor market attribute indices in such a way that they do not depend on geographic units. If economic activities were evenly distributed over space and if there were no spatial attenuation, the effects of human capital externalities would be the same at different locations. If estimated coefficients for an index vary with distance, we can infer its spatial pattern. We divide rings of different miles away from the centroid of each block and construct indices based on the workers in each ring. There is no prior guidance on how to determine the number and the width of rings, except through experimentation. A rule of thumb is to look at the size distribution of blocks, blockgroups, and tracts. In the seven counties included in the BMA, if we assume blocks, blockgroups, and tracts were circles, then about $95 \%$ of blocks are within circles of 0.3 mile radius, $95 \%$ blockgroups are within circles of 1.3 miles radius, and $98 \%$ tracts are within circles of 3 miles radius. However, the size distributions of blocks, blockgroups, and tracts are very dispersed. We first, tentatively, divide rings of 1.5, 3, 6 , and 9 miles away from each block centroid. Blocks themselves consist of the inner ring, blocks within distance $(0,1.5]$ miles consist of the second ring, which corresponds approximately to the blockgroup level. Blocks within distance $(1.5,3]$ miles belong to the third ring, corresponding to the tract level; $(3,6]$ and $(6,9]$ miles annulus are the fourth and fifth ring. We estimate the spatial attenuation model including all the indices for all the rings. The results are reported in Table 7 . 
TABLE 7

Spatial Attenuation Model (5 Rings)

\begin{tabular}{|c|c|c|c|c|c|c|}
\hline & \multicolumn{2}{|c|}{ Model 1: $N>1$} & \multicolumn{2}{|c|}{ Model 2: $N>10$} & \multicolumn{2}{|c|}{ Model 3: $N>20$} \\
\hline Variable & Coefficient & Std.error & Coefficient & Std. error & Coefficient & Std.error \\
\hline AveEdu0 & 0.0708 & 0.0120 & 0.1496 & 0.0067 & 0.1736 & 0.0076 \\
\hline AveEdu1 & 0.1406 & 0.0453 & 0.1081 & 0.0476 & $(0.0667)$ & 0.0556 \\
\hline AveEdu3 & 0.1034 & 0.0584 & $(0.0621)$ & 0.0740 & $(0.1012)$ & 0.0794 \\
\hline AveEdu6 & $(0.0214)$ & 0.0567 & $(0.0603)$ & 0.0733 & $(0.0213)$ & 0.0789 \\
\hline AveEdu9 & $(0.0662)$ & 0.0584 & $(-0.0062)$ & 0.0494 & $(0.0140)$ & 0.0686 \\
\hline OccSpec0 & 0.0535 & 0.0213 & 0.0874 & 0.0259 & 0.0816 & 0.0462 \\
\hline OccSpec1 & 0.2227 & 0.0850 & 0.1924 & 0.0835 & 0.2475 & 0.0844 \\
\hline OccSpec3 & -0.3597 & 0.1912 & -0.3837 & 0.2356 & -0.4632 & 0.2463 \\
\hline OccSpec6 & $(-0.0298)$ & 0.1417 & $(-0.0954)$ & 0.1456 & $(-0.0066)$ & 0.0774 \\
\hline OccSpec9 & $(0.2900)$ & 0.2619 & $(0.3862)$ & 0.3138 & $(0.3168)$ & 0.2807 \\
\hline IndSpec0 & 0.0602 & 0.0075 & 0.0555 & 0.0061 & 0.0626 & 0.0096 \\
\hline IndSpec1 & $(-0.0039)$ & 0.0102 & $(0.0036)$ & 0.0087 & $(-0.0111)$ & 0.0126 \\
\hline IndSpec3 & 0.0948 & 0.0537 & 0.0989 & 0.0558 & 0.1028 & 0.0565 \\
\hline IndSpec6 & 0.1773 & 0.0715 & 0.1840 & 0.0967 & 0.2067 & 0.0871 \\
\hline IndSpec9 & $(-0.0296)$ & 0.0494 & $(-0.0039)$ & 0.0394 & $(0.0179)$ & 0.0448 \\
\hline OccDiver0 & 0.1438 & 0.0271 & $(0.0384)$ & 0.0496 & $(-0.0063)$ & 0.0368 \\
\hline OccDiver1 & $(0.0859)$ & 0.1484 & $(0.2061)$ & 0.1820 & $(0.1313)$ & 0.2246 \\
\hline OccDiver3 & -0.3742 & 0.2288 & $(-0.3393)$ & 0.2898 & $(-0.2665)$ & 0.3125 \\
\hline OccDiver6 & $(0.1223)$ & 0.9250 & $(0.0040)$ & 0.9687 & $(0.1841)$ & 1.1019 \\
\hline OccDiver9 & 1.1618 & 0.4064 & 0.9068 & 0.3867 & 0.8317 & 0.4675 \\
\hline IndDiver0 & 0.0637 & 0.0162 & 0.0810 & 0.0244 & 0.0992 & 0.0192 \\
\hline IndDiver 1 & 0.2735 & 0.0813 & 0.2944 & 0.0934 & 0.2896 & 0.1059 \\
\hline IndDiver3 & 0.2203 & 0.0906 & 0.2160 & 0.1051 & 0.2364 & 0.1175 \\
\hline IndDiver6 & 0.3004 & 0.1211 & 0.2755 & 0.0943 & 0.3075 & 0.1477 \\
\hline IndDiver9 & $(0.1862)$ & 0.01486 & $(0.1205)$ & 0.1123 & $(0.1797)$ & 0.1491 \\
\hline OccDens0 & 0.0064 & 0.0002 & 0.0053 & 0.0001 & 0.0051 & 0.0004 \\
\hline OccDens1 & -0.0569 & 0.0065 & -0.0510 & 0.0096 & -0.0484 & 0.0106 \\
\hline OccDens3 & 0.0784 & 0.0301 & 0.1621 & 0.0290 & 0.1382 & 0.0268 \\
\hline OccDens6 & $(-0.0973)$ & 0.1672 & $(-0.2069)$ & 0.1497 & -0.2116 & 0.1208 \\
\hline OccDesn9 & $(-0.0918)$ & 0.3432 & $(-0.0091)$ & 0.2312 & $(0.1943)$ & 0.2654 \\
\hline IndDens0 & 0.0020 & 0.0006 & 0.0021 & 0.0006 & 0.0018 & 0.0006 \\
\hline IndDens1 & 0.0675 & 0.0190 & 0.0542 & 0.0174 & 0.0411 & 0.0205 \\
\hline IndDens3 & -0.2428 & 0.0567 & -0.2747 & 0.0619 & -0.2678 & 0.0739 \\
\hline IndDens6 & $(-0.0105)$ & 0.0432 & $(0.0210)$ & 0.0565 & $(0.0278)$ & 0.0761 \\
\hline IndDens9 & $(0.0153)$ & 0.1106 & $(-0.0837)$ & 0.0924 & -0.2644 & 0.1203 \\
\hline Observations & 145230 & & 123211 & & 107847 & \\
\hline$R^{2}$ & 0.332 & & 0.345 & & 0.354 & \\
\hline
\end{tabular}

Note: ( ) indicates insignificance at the 10\% level. Standard error clusters: 7 counties. $N$ : number of workers in a block. 
Numbers $0,1,3,6,9$ at the end of each variable name indicate that the construction of that variable is based on the employment within the block, ring of $1.5,3,6$, and 9 miles respectively. Model 1 in Table 7 selects only blocks where the number of workers is greater than one. Let us first look at the overall quality of human capital. The variable AveEdu is geographic-invariant. If there were no spatial attenuation, the coefficients should be the same at different rings. The coefficients of AveEdu are actually .071, .141, .103, .021, and .066, respectively from the inner ring to the 9 miles ring. The first two coefficients are significant at the $1 \%$ level, the third one is significant at the $10 \%$ level, but the other two coefficients are not significant. The coefficient at the block level (.071) probably is underestimated due to measurement errors. Though we do not know how strong the actual effect is at the block level, we could infer that the effects of human capital depth are positive and significant up to three miles away from each block. then they decay rapidly thereafter (decrease by 5 times from the third to the fourth ring). This pattern is also consistent with Table 5.

The effects of occupation specialization decay very fast beyond 1.5 miles, which implies that the occupational Marshallian externalities are very localized. The industrial specialization effects are significant up to the sixth mile, and not significant thereafter, consistent with Table 5 where industrial specialization effects are very stable within tract levels.

The coefficients of occupation employment density are large and significant at the tract level, insignificant beyond tract level. The coefficients of industry employment density show a similar pattern: large and significant at the blockgroup level, then they decay rapidly.

The pattern of diversity indices is worth noting. The coefficients of occupation diversity are the strongest and significant at the farthest ring. The coefficients of industrial diversity are positive and significant at the first four rings, and the variation of magnitude is not very large $(.064, .274, .220, .300 \mathrm{in}$ the first four rings). These patterns hint that there exist strong urbanization economies within certain geographic scopes due to urban diversity. 
The above results show that human capital externalities in cities have obvious spatial attenuation patterns, though they may be strong at different geographic scopes and decay at different speeds. Note that the monocentric city model predicts that spatial decay effects occur with distance away from the Central Business District (CBD). However, in our model, we construct rings for each block, no matter whether the block is located in downtown or in a suburban area. Therefore, our results provide much stronger and more powerful evidence for the spatial attenuation of local agglomeration economies.

Are our results sensitive to the scale of block employment concentration? We also estimate the same model using blocks where there are more than 10 workers and 20 workers, respectively, see model 2 and 3 in Table 7 . Again we find that the coefficients at the block level (the inner ring) increase significantly, probably due to measurement errors. Though the magnitude of coefficients changed, the spatial decay patterns are almost the same.

We also estimate the spatial attenuation model with tract and blockgroup fixed effects. The results are presented in Table 8. 
TABLE 8

Spatial Attenuation Model With Different Fixed Effects

\begin{tabular}{|c|c|c|c|c|}
\hline \multirow[t]{2}{*}{ Fixed effects } & \multicolumn{2}{|c|}{ Tract } & \multicolumn{2}{|c|}{ Blockgroup } \\
\hline & Coefficient & Std.error & Coefficient & Std. error \\
\hline AveEdu0 & 0.0392 & 0.0152 & 0.0296 & 0.0172 \\
\hline AveEdu1 & $(-0.1278)$ & 0.0868 & -0.3624 & 0.1396 \\
\hline AveEdu3 & $(0.0637)$ & 0.1266 & $(-0.0449)$ & 0.1573 \\
\hline AveEdu6 & $(-0.0725)$ & 0.1965 & $(-0.0221)$ & 0.3237 \\
\hline AveEdu9 & $(-0.0511)$ & 0.2193 & $(0.0878)$ & 0.3345 \\
\hline OccSpec0 & 0.0578 & 0.0196 & 0.0603 & 0.0201 \\
\hline OccSpec1 & 0.2207 & 0.0792 & 0.2003 & 0.0753 \\
\hline OccSpec3 & -0.3491 & 0.1385 & -0.3519 & 0.1138 \\
\hline OccSpec6 & $(-0.0915)$ & 0.1768 & $(-0.1265)$ & 0.1647 \\
\hline OccSpec9 & 0.3527 & 0.1610 & 0.3688 & 0.1600 \\
\hline IndSpec0 & 0.0536 & 0.0124 & 0.0565 & 0.0127 \\
\hline IndSpec1 & $(-0.0029)$ & 0.0253 & $(-0.0172)$ & 0.0268 \\
\hline IndSpec3 & 0.0826 & 0.0430 & 0.0871 & 0.0396 \\
\hline IndSpec6 & 0.1139 & 0.0632 & 0.1493 & 0.0612 \\
\hline IndSpec9 & $(0.0400)$ & 0.0699 & $(0.0140)$ & 0.0675 \\
\hline OccDiver0 & 0.1351 & 0.0317 & 0.1398 & 0.0319 \\
\hline OccDiver1 & -0.5065 & 0.2589 & $(0.2214)$ & 0.3480 \\
\hline OccDiver3 & -0.7117 & 0.3110 & $(-0.4354)$ & 0.6218 \\
\hline OccDiver6 & $(0.1882)$ & 1.215 & $(1.0808)$ & 1.7819 \\
\hline OccDiver9 & $(0.6878)$ & 1.3032 & $(1.7476)$ & 1.7778 \\
\hline IndDiver0 & 0.0325 & 0.0175 & 0.0416 & 0.0192 \\
\hline IndDiver1 & $(0.0616)$ & 0.1057 & $(0.1576)$ & 0.1400 \\
\hline IndDiver3 & $(0.1256)$ & 0.1635 & $(0.0637)$ & 0.2294 \\
\hline IndDiver6 & $(-0.2208)$ & 0.4160 & $(-0.6970)$ & 0.5972 \\
\hline IndDiver9 & $(0.3289)$ & 0.4221 & $(0.6386)$ & 0.6021 \\
\hline OccDens0 & 0.0046 & 0.0014 & 0.0043 & 0.0017 \\
\hline OccDens1 & $(-0.0500)$ & 0.0344 & $(-0.0452)$ & 0.0334 \\
\hline OccDens3 & $(0.0924)$ & 0.1150 & $(0.0643)$ & 0.0997 \\
\hline OccDens6 & $(0.0118)$ & 0.2232 & $(0.0422)$ & 0.1988 \\
\hline OccDens9 & $(-0.2439)$ & 0.2793 & $(-0.1506)$ & 0.2800 \\
\hline IndDens0 & 0.0025 & 0.0009 & 0.0022 & 0.0010 \\
\hline IndDens1 & 0.0790 & 0.0276 & 0.0738 & 0.0289 \\
\hline IndDens3 & -0.1935 & 0.0740 & -0.2129 & 0.0700 \\
\hline IndDens6 & $(0.0690)$ & 0.1504 & $(0.1151)$ & 0.1334 \\
\hline IndDens9 & $(-0.1695)$ & 0.2179 & $(-0.1328)$ & 0.2114 \\
\hline$R^{2}$ & 0.338 & & 0.350 & \\
\hline S.E. clusters & Tract (610) & & Blockgroup & \\
\hline
\end{tabular}

Note: ( ) indicates insignificance at the 10\% level. Observations: 142530.

After controlling for tract or blockgroup specific effects, most coefficients are positive and significant only at the first and/or the second ring (block and/or 
blockgroup level), which makes the spatial attenuation pattern less neat. This, however, further confirms our identification strategy that the tract fixed effects model identifies agglomeration effects across blockgroups and the blockgroup fixed effects model identifies agglomeration effects across blocks.

Are our results sensitive to the number and width of rings? We also estimate the spatial decay model by dividing 5 rings of 2 miles intervals and 6 rings of 1 or 2 miles intervals. The results (not reported here) are pretty similar. We also estimate the spatial attenuation model by industry and occupation. The results (not reported here) are mixed since human capital externalities vary across occupations and industries.

\section{Conclusion}

Endogenous growth and urban theories assume the existence of human capital externalities. Urban theoretical models further predict that agglomeration forces attenuate spatially. In this paper, we use the 1990 Massachusetts census data and provide empirical evidence for the microfoundations and spatial attenuation patterns of knowledge spillovers at microgeographic levels. We test four channels through which individual workers can learn from their occupational and industrial peers in the same local labor market: depth of the human capital stock, Marshallian labor market externalities, Jacobs labor market externalities, and thickness of the local labor market. We find that all types of human capital externalities are strong and significant across census tracts and blocks; Marshallian labor market externalities and the effect of labor market thickness in terms of industry employment density are significant at the block level. Different types of externalities decay at different speeds over geographic distances. We conclude that knowledge spillovers are very localized within microgeographic scope in cities that we call, "Smart Café Cities."

Some related questions may warrant further research. Though we use Marshallian and Jacobs externalities of labor markets in our model, we actually estimated a cross-section model. The next stage would be to test the dynamics 
of human capital externalities. Simon et al. (2002) found considerable persistence of the effects of human capital, indicating that the distribution of human capital established in the first decade of the twentieth century played a role in the current status of American cities. They also found that the presence of human capital is less important today than in the past, perhaps reflecting the decline in the costs of transportation and communication. However, Gaspar and Glaeser (1998) argued that information technology and face-to-face interactions could be complements rather than substitutes. Empirical testing of the effects of information technology on knowledge spillovers would be a very interesting topic in the near future. Finally, but not least important, since human capital externalities can be capitalized into housing values, it would be interesting to estimate a hedonic housing model by including labor market attributes to test Lucas conjecture. ${ }^{12}$ We are making progress on this topic.

\footnotetext{
${ }^{12}$ Lucas (2001, p.270-271) wrote "...an externality-based theory of cities might let us use the information contained in urban land price gradients to estimate the size of the externalities associated with human capital accumulation."
} 


\section{References}

[1] Anselin, Luc, 1988, Spatial Econometrics, Methods and Models, Boston: Kluwer Academic Publishers.

[2] Barro, Robert and Xavier Sala-I-Martin, 1995, Economic Growth, McGrawHill, Inc.

[3] Bayer, Patrick, Stephen Ross, and Giorgio Topa, 2004, Place of Work and Place of Residence: Informal Hiring Networks and Labor Market Outcomes, Working Paper.

[4] Beeson, Patricia, David Delong, and Werner Troesken, 1999, Population Growth in U.S. Counties, 1840-1990, Working Paper, University of Pittsburgh.

[5] Berliant, Marcus, Robert Reed, and Ping Wang, 2002, Knowledge Exchange, Matching, and Agglomeration, Working Paper, Washington University.

[6] Black, Duncan and Vernon Henderson, 1999, A Theory of Urban Growth, Journal of Political Economy 107, 252-84.

[7] Charlot, Sylvie and Gilles Duranton, 2003, Communication Externalities in Cities, Working Paper.

[8] Ciccone, Antonio and Robert Hall, 1996, Productivity and the Density of Economic Activity, American Economic Review 86, no.1, 55-70.

[9] Duranton, Gilles and Henry Overman, 2002, Testing For Localization Using Microgeographic Data, CEPR Working Paper No.3379.

[10] Duranton, Gilles and Diego Puga, 2000, Diversity and Specialization in Cities, Why, Where and When Does it Matter? Urban Studies 37, no.3, $533-55$.

[11] Duranton, Gilles and Diego Puga, 2003, Micro-foundations of Urban Agglomeration Economies, Handbook of Regional and Urban Economics, Vol.4, forthcoming, Elsevier.

[12] Eaton, Jonathan and Zvi Eckstein, 1997, Cities and Growth: Theory and Evidence From France and Japan, Regional Science and Urban Economics $27,443-474$.

[13] Florida, Richard, 2000, The Economic Geography of Talent, Working Paper, Carnegie Mellon University.

[14] Florida, Richard, 2002, Bohemia and Economic Geography, Journal of Economic Geography 2, 55-71. 
[15] Fujita, Masahisa, and Hideaki Ogawa, 1982, Multiple Equilibria and Structural Transition of Non-Monocentric Urban Configurations, Regional Sciences and Urban Economics 12, 161-96.

[16] Fujita, Masahisa, Paul Krugman, and Anthony Venables, 1999, The Spatial Economy, The MIT Press.

[17] Gaspar, Jess and Glaeser Edward, 1998, Information Technology and the Future of Cities, Journal of Urban Economics 43, 136-56.

[18] Gibbons, Steve and Stephen Machin, 2003, Valuing English Primary Schools, Journal of Urban Economics 53, 197-219.

[19] Glaeser, Edward, Hedi Kallal, Jose Scheinkman, and Andrei Shleifer, 1992, Growth in Cities, Journal of Political Economy 100, no.6, 1126-1152.

[20] Helsley, Robert and William Strange, 1990, Matching and Agglomeration Economies in a System of Cities, Regional Science and Urban Economics $20,189-212$.

[21] Henderson, Vernon, 1974, The Sizes and Types of Cities, American Economic Review 64, no.4, 640-56.

[22] Henderson, Vernon, 2003, Marshall's Scale Economies, Journal of Urban Economics 53, 1-28.

[23] Jacobs, Jane, 1969, The Economy of Cities, New York: Vintage Books.

[24] Jaffe, Adam, Manuel Trajtenberg, and Rebecca Henderson, 1993, Geographic Localization of Knowledge Spillovers as Evidenced by Patent Citations, Quarterly Journal of Economics 108, 577-98.

[25] Jovanovic, Boyan and Rafael Rob, 1989, The Growth and Diffusion of Knowledge, Review of Economic Studies 56, 569-82.

[26] Lucas, Robert E., Jr., 1988, On the Mechanics of Economic Development, Journal of Monetary Economics 22, 3-42.

[27] Lucas, Robert, E., Jr., 2001, Externalities and Cities, Review of Economic Dynamics 4, 245-74.

[28] Maggioni, Mario, 2002, Clustering Dynamics and the Location of HighTech-Firms, Physica-Verlag Heidelberg, New York.

[29] Marshall, Alfred, 1920, Principles of Economics (8th edn). London: Macmillan.

[30] Morettie, Enrico, 2003, Human Capital Externalities in Cities, NBER Working Paper 9641.

[31] Palivos, Theodore and Ping Wang, 1996, Spatial Agglomeration and Endogenous Growth, Regional Science and Urban Economics 26, 645-69. 
[32] Porter, Michael, 1990, The Competitive Advantage of Nations, New York: Free Press.

[33] Porter, Michael, 1998, Clusters and the New Economics of Competition, Harvard Business Review, Nov.-Dec., 77-90.

[34] Quigley, John, 1998, Urban Diversity and Economic Growth, Journal of Economic Perspectives 12, no.2, 127-38.

[35] Rauch, James, 1993, Productivity Gains From Geographic Concentration of Human Capital: Evidence from Cities, Journal of Urban Economics 34, $380-400$.

[36] Romer, Paul, 1986, Increasing Returns and Long-Run Growth, Journal of Political Economy 94, 1002-37.

[37] Rosenthal, Stuart and William Strange, 2001, The Determinants of Agglomeration, Journal of Urban Economics 50, 191-229.

[38] Rosenthal, Stuart and William Strange, 2003a, Geography, Industrial Organization, and Agglomeration, Review of Economics and Statistics 85, $377-93$.

[39] Rosenthal, Stuart and William Strange, 2003b, Evidence on the Nature and Sources of Agglomeration Economies, Handbook of Urban and Regional Economics, Vol.4, forthcoming, Elsevier.

[40] Shapiro, Jesse, 2003, Smart Cities: Explaining the Relationship Between City Growth and Human Capital, Harvard University.

[41] Simon, Curtis and Clark Nardinelli, 2002, Human Capital and the Rise of American Cities: 1900-1990, Regional Science and Urban Economics 32, 59-96.

[42] Timothy, Darren and William Wheaton, 2001, Intra-Urban Wage Variation, Employment Location, and Commuting Times, Journal of Urban Economics 50, 338-66.

[43] Wheaton, William and Mark Lewis, 2002, Urban Wages and Labor Market Agglomeration, Journal of Urban Economics 51, 542-562. 


\section{Appendix}

TABLE A-1

Some Summary Statistics

\begin{tabular}{lcccc}
\hline \hline & Mean & Std. deviation & Min. & Max. \\
\hline Number of workers in a tract & 242 & 485 & & 8527 \\
Number of workers in a blockgroup & 61 & 151 & & 2664 \\
Number of workers in a block & 13 & 40 & 1003 \\
Number of blockgroups in a tract & 4.0 & 1.7 & 1 & 9 \\
Number of blocks in a blockgroup & 4.6 & 3.3 & 1 & 25 \\
Mean hourly wage in a tract & 14.49 & 3.4 & & \\
Mean hourly wage in a blockgroup & 14.54 & 7.14 & & \\
Mean hourly wage in a block & 14.42 & 10.42 & & \\
\hline \hline
\end{tabular}

TABLE A-2

Industry Code

\begin{tabular}{ll}
\hline \hline Industry & 1990 census code \\
\hline Construction & $60-99$ \\
Manufacturing & $100-399$ \\
Public utility & $400-499$ \\
Wholesale trade & $500-579$ \\
Retail trade & $580-699$ \\
Finance,real estate, insurance & $700-720$ \\
Business and repair services & $721-760$ \\
Personal services & $761-799$ \\
Entertainment & $800-811$ \\
Professional services & $812-899$ \\
Public administration & $900-939$ \\
Computer & $732-739$ \\
High-tech industry* & $181,321-330,352-359$ \\
& $362-369,371-380$ \\
\hline \hline
\end{tabular}

*: The classification of high-tech industry is based on Maggioni(2002). 
TABLE A-3

Occupation Code

\begin{tabular}{ll}
\hline \hline Occupation & 1990 Census code \\
\hline Managerial, professional specialty & $1-42$ \\
Engineers, architects, surveyors & $43-63$ \\
Mathematical, computer scientists & $64-68$ \\
Natural scientists & $69-83$ \\
Health diagnosing occupation & $84-112$ \\
Teachers, librarians, archivists & $113-165$ \\
Social scientists, urban planners & $166-182$ \\
Writers, artists, entertainers, athletes & $183-202$ \\
Technicians & $203-242$ \\
Sales & $243-302$ \\
Administrative & $303-402$ \\
Service & $403-472$ \\
Mechanics, repairers & $503-552$ \\
Construction & $553-612$ \\
Precision production & $628-702$ \\
Machine operators, tenders & $703-802$ \\
Transportation, material moving & $803-863$ \\
Handlers, equipment cleaners,laborers & $864-902$ \\
\hline \hline
\end{tabular}


TABLE A-4

Summary Statistics for Selected Industries and Occupations

\begin{tabular}{llcc}
\hline \hline & Index & Mean & Std. deviation \\
\hline Managerial & AveEduOcc & 0.601 & 0.195 \\
professional specialty & OccSpec & 0.153 & 0.060 \\
& OccDens & 0.039 & 0.138 \\
\hline Writers, artists & AveEduOcc & 0.673 & 0.326 \\
entertainers, athletes & OccSpec & 0.027 & 0.022 \\
& OccDens & 0.008 & 0.023 \\
\hline Mathematical & AveEduOcc & 0.817 & 0.284 \\
computer scientists & OccSpec & 0.017 & 0.017 \\
& OccDens & 0.006 & 0.018 \\
\hline Manufacturing & AveEduInd & 0.372 & 0.247 \\
& IndSpec & 0.136 & 0.120 \\
& IndDens & 0.022 & 0.051 \\
\hline Finance, insurance & AveEduInd & 0.438 & 0.260 \\
real estate & IndSpec & 0.080 & 0.067 \\
& IndDens & 0.025 & 0.135 \\
\hline Retail & AveEduInd & 0.253 & 0.168 \\
& IndSpec & 0.174 & 0.091 \\
& IndDens & 0.027 & 0.058 \\
\hline Overall & AveEdu & 0.419 & 0.126 \\
& OccDiver & 0.864 & 0.057 \\
\hline \hline & IndDiver & 0.759 & 0.105 \\
\hline
\end{tabular}

TABLE A-5

Correlation Matrix

\begin{tabular}{lccccccccc}
\hline \hline & $\begin{array}{c}\text { Ave. } \\
\text { Edu. }\end{array}$ & $\begin{array}{c}\text { AveEdu. } \\
\text { Occ. }\end{array}$ & $\begin{array}{c}\text { AveEdu. } \\
\text { Ind. }\end{array}$ & $\begin{array}{c}\text { Occ. } \\
\text { Spec. }\end{array}$ & $\begin{array}{c}\text { Ind. } \\
\text { Spec. }\end{array}$ & $\begin{array}{c}\text { Occ. } \\
\text { Diver. }\end{array}$ & $\begin{array}{c}\text { Ind. } \\
\text { Diver. }\end{array}$ & $\begin{array}{c}\text { Occ. } \\
\text { Dens. }\end{array}$ & $\begin{array}{c}\text { Ind. } \\
\text { Dens. }\end{array}$ \\
\hline AveEdu & 1.000 & & & & & & & & \\
AveEduOcc & 0.386 & 1.000 & & & & & & & \\
AveEduInd & 0.563 & 0.519 & 1.000 & & & & & & \\
OccSpec & 0.044 & -0.018 & 0.049 & 1.000 & & & & & \\
IndSpec & 0.164 & 0.241 & 0.390 & 0.118 & 1.000 & & & & \\
OccDiver & -0.161 & -0.062 & -0.090 & -0.271 & -0.088 & 1.000 & & & \\
IndDiver & -0.289 & -0.112 & -0.163 & -0.042 & -0.566 & 0.156 & 1.000 & & \\
OccDens & 0.360 & 0.142 & 0.223 & 0.376 & 0.002 & -0.313 & 0.041 & 1.000 & \\
IndDens & 0.432 & 0.247 & 0.399 & 0.124 & 0.333 & -0.291 & -0.175 & 0.670 & 1.000 \\
\hline \hline
\end{tabular}

